\title{
Chemometric Characterization of Almond Germplasm: Compositional Aspects Involved in Quality and Breeding
}

\author{
Ossama Kodad, José M. Alonso, and María T. Espiau \\ Unidad de Fruticultura, Centro de Investigación y Tecnología Agroalimentaria de Aragón (CITA), \\ Av. Montañana 930, 50059 Zaragoza, Spain \\ Gloria Estopañán and Teresa Juan \\ Unidad de Calidad y Seguridad Alimentaria, CITA de Aragón, Av. Montañana 930, 50059 Zaragoza, \\ Spain \\ Rafel Socias i Company ${ }^{1}$ \\ Unidad de Fruticultura, CITA de Aragón, Av. Montañana 930, 50059 Zaragoza, Spain
}

Additional INDEX words. Prunus amygdalus, kernel quality, oil content, fatty acids

\begin{abstract}
The oil content and the percentage of the main fatty acids were determined in a set of 73 almond (Prunus amygdalus Batsch) cultivars from 10 different countries present at the almond germplasm collection of the Centro de Investigación y Tecnología Agroalimentaria de Aragón, Spain (CITA). Wide variability was observed for oil content, ranging from $51.5 \%$ to $66.8 \%$ on a dry weight (DW) basis. For the main fatty acids in the lipid fraction, the variability ranged from $62.9 \%$ to $77.3 \%$ for oleic acid, from $14.0 \%$ to $26.8 \%$ for linoleic acid, from $4.9 \%$ to $7.0 \%$ for palmitic acid, from $1.5 \%$ to $3.4 \%$ for stearic acid, and from $0.3 \%$ to $0.6 \%$ for palmitoleic acid. No correlations were found between the oil content and the percentages of the different fatty acids, but a significant negative correlation was found between the percentages of oleic and linoleic acids. Principal component (PC) analysis showed that palmitic, oleic, and linoleic acids and the oleic acid/linoleic acid ratio were primarily responsible for the separation on principal component 1 . The content of each component was not related to the country of origin of the different cultivars, indicating that almond fatty acid composition is genotype-dependent. Cultivars with high and stable oil content and low linoleic acid should be selected as parents in a breeding program to increase kernel oil stability and nutritional value.
\end{abstract}

Almond is the most important tree nut crop in terms of commercial production. This production is limited to areas characterized by a Mediterranean climate (Kester and Asay, 1975), including regions in the Mediterranean countries, the Central Valley of California, the Middle East, and some equivalent areas in the Southern Hemisphere. Traditional almond culture used open-pollinated seedlings (Grasselly, 1972; Rikhter, 1972), which, together with self-incompatibility, produced very high heterozygosity in this species (Kester et al., 1990; Socias i Company and Felipe, 1992). This large variability has provided a useful genetic pool for almond evolution, allowing in each growing region the selection of almond cultivars well-adapted to this area (Kester et al., 1990). However, some cultivars have shown high plasticity, being adapted to different growing conditions (Felipe, 2000). Several characteristics (fruit traits, blooming date, productivity, resistance to pests and diseases, etc.) were taken into account by human selection pressure when looking for the adequate genotypes adapted to local conditions and to the preference of the consumers. The genotypes having incorporated these highly selected traits represent very valuable germplasm for addressing future challenges in almond breed-

Received for publication 26 Apr. 2011. Accepted for publication 8 June 2011. This work was supported by Spanish grants AGL2010-22197-C02-01 and INIA RF2008-00027-00-00, European grant AGRI GEN RES 870/2004 068 (SAFENUT), and Research Group A12 of Aragón.

Technical assistance by J. Búbal and O. Frontera is highly appreciated.

1Corresponding author. E-mail: rsocias@aragon.es. ing. As a consequence, these genotypes are preserved, characterized in several almond collections and incorporated into advanced breeding programs (Kester et al., 1990).

One of the most important collections was initially assembled by A.J. Felipe at CITA with $\approx 250$ accessions introduced from all over the world (Espiau et al., 2002). This collection shows very large variability reflecting the wide genetic diversity of almond (Socias i Company and Felipe, 1992). Despite the large amount of information on these accessions, the chemical composition of their kernels has only been partially studied. This information would be crucial to increase the knowledge of their diversity, the nutritional and healthy value of the kernels, and the possibility of selecting the most adequate parents in a breeding program for increasing kernel quality (Socias i Company et al., 2008). The modern almond industry requires commercial cultivars characterized by kernels with high-quality attributes, because the best end use for each cultivar is a function of its chemical composition (Berger, 1969) and of the consumers' trend for foods without synthetic additives (Krings and Berger, 2001). Thus, the CITA almond breeding program has incorporated the chemical quality criteria in the evaluation of the new cultivars (Socias $i$ Company et al., 2009).

The high nutritive value of almond kernels arises mainly from their high lipid content, which constitutes an important caloric source but does not contribute to cholesterol formation in humans. This is the result of their high level of unsaturated fatty acids, mainly monounsaturated fatty acids (MUFA), because MUFAs are inversely correlated with serum cholesterol 
levels (Sabate and Hook, 1996). Kernel tendency to rancidity during storage and transport is a quality loss and is related to oxidation of the kernel fatty acids (Senessi et al., 1996). Thus, oil stability and fatty acid composition, essentially the oleic acid/ linoleic acid (O/L) ratio (Kester et al., 1993), is considered an important criterion to evaluate kernel quality. The determination of kernel oil quality, taking into account both its content and composition, is an imperative step in the evaluation of new cultivars before being released (Socias i Company et al., 2008).

Recent studies on the transmission and heritability of oil content, fatty acid composition, and the different tocopherol homologs (Font i Forcada et al., 2011) have shown that oil content presents high heritability values (57\%) and linoleic acid a medium value $(25 \%)$. When heritability estimates are moderate, selection of parents based on their phenotypes should also be effective, as it happens when heritability is high (Hansche et al., 1972). Kernels with a high percentage of oil could be used to produce nougat or to extract oil, which is used in the cosmetic and pharmaceutical industries (Socias i Company et al., 2008). In addition, high oil content is desirable because higher oil contents result in less water absorption by the almond paste (Alessandroni, 1980). Low content of linoleic acid is correlated with high oil stability (Zacheo et al., 2000). Thus, selection of parents for low linoleic acid and high oil content might be undertaken in a breeding program for increased kernel quality.

Thus, our main objective was the study of the genetic diversity for oil content and fatty acid composition of the almond cultivars included in the CITA collection to ascertain the best genotypes from the point of view of oil quality. These choice genotypes should be included as parents in breeding programs aiming at improving almond kernel quality.

\section{Material and Methods}

Plant material. The list of the 73 almond cultivars studied is shown in Table 1. The trees are maintained as living plants grafted on the almond $\times$ peach [Prunus persica (L.) Batsch] hybrid clonal rootstock INRA GF-677 using standard management practices (Espiau et al., 2002). Nuts from open pollination were harvested in 2008 and 2009 at the mature stage, when fruit mesocarp was fully dried and split along the fruit suture and peduncle abscission was complete (Felipe, 1977). Two samples of 20 fruit were collected for each treatment.

Oil AND FATTY ACID Determination. After blanching, the kernels were ground in an electrical grinder. Oil was extracted from 4 to $5 \mathrm{~g}$ of ground almond kernel in the commercial fat extractor Soxtec Avanti 2055 (Tecator, Barcelona, Spain) for $2 \mathrm{~h}$ using petroleum ether as a solvent and keeping the heating source at $135{ }^{\circ} \mathrm{C}$ because previous checks showed that extraction is practically completed after $2 \mathrm{~h}$ with no differences after $4 \mathrm{~h}$ (Kodad and Socias i Company, 2008). The oil content was expressed as the difference in weight of the dried kernel sample before and after extraction. The oil sample was used to prepare methyl esters of the corresponding fatty acids (FAMEs) by transetherification with $\mathrm{KOH}$ according to the official method UNE-EN ISO 5509:2000 (International Organization for Standardization, 2000). These FAMEs were separated using a flame ionization detector gas chromatograph HP-6890 equipped with a HP-Innowax column of $30 \mathrm{~m} \times 0.25 \mathrm{~mm}$ i.d. and $0.25-\mu \mathrm{m}$ film thickness (Agilent Technologies, Waldbronn, Germany). The carrier gas was helium at a flow rate of $1 \mathrm{~mL} \cdot \mathrm{min}^{-1}$. The temperature of the inlet and detector was maintained at 220 and $275^{\circ} \mathrm{C}$, respectively. The initial column temperature was $100{ }^{\circ} \mathrm{C}$ for $3 \mathrm{~min}$. The oven temperature was increased from 100 to $150{ }^{\circ} \mathrm{C}$ at $20{ }^{\circ} \mathrm{C} \cdot \mathrm{min}^{-1}$ ramp rate for $1 \mathrm{~min}$, from 150 to $200{ }^{\circ} \mathrm{C}$ at $15^{\circ} \mathrm{C} \cdot \mathrm{min}^{-1}$ ramp rate for $3 \mathrm{~min}$, and from 200 to $240{ }^{\circ} \mathrm{C}$ at $3{ }^{\circ} \mathrm{C} \cdot \mathrm{min}^{-1}$ ramp rate. The temperature was maintained at $240{ }^{\circ} \mathrm{C}$ for $4 \mathrm{~min}$. Injection volume was $1.0 \mathrm{~mL}$. The identification of the FAMEs was achieved by comparing with relative chromatographic retention times in a reference sample that contained standard methyl esters (Sigma-Aldrich, Madrid, Spain). The results were expressed as percentages of each fatty acid in the total oil amount.

Statistical ANALYSIS. All statistical analyses were performed with SAS (Version 9.1; SAS Institute, Cary, NC). The analysis of variance with the PROC GLM procedure was applied to evaluate the genotype and year effect on the studied variable. The mean separation was done with the least significant difference test at a probability of 0.05 . The LSMEANS option of the GLM procedure was used to calculate least-square means for genotypes in each year to observe rank changes of genotypes from year to year. Principal component analysis (PCA) was performed to study correlation among fruit quality measurements and to interpret relationships between genotypes as a tool for germplasm characterization (Gurrieri et al., 2001; Iezzoni and Pritts, 1991). PCA analyses were performed on the correlation matrix of the synthetic variable based on the mean population value (Prosperi et al., 2006) using the PRINCOMP procedure. Pearson's correlation coefficients were calculated with the PROC CORR procedure.

\section{Results and Discussion}

GENOTYPIC VARIABILITY. Large differences in oil content and major fatty acids were found among the cultivars studied (Table 1). The mean value of oil content over the 2 years varied from $51.54 \%$ of DW in 'Siria-3' to $66.79 \%$ in 'Filippo Ceo'. When the range of variability of oil content was studied in cultivars from the same geographical origin, the results showed that this range was large in the genetic pool from Spain $(54.77 \%$ to $66.39 \%)$, medium for France $(54.79 \%$ to $64.72 \%)$ and Italy (56.21\% to $66.79 \%$ ), and low for Portugal $(58.33 \%$ to $63.66 \%)$ and the United States $(57.37 \%$ to $63.61 \%)$. It is significant to note that almost all cultivars from France, Italy, and the United States have a mean value of oil content higher than $60 \%$. The range of oil content variability for the cultivars from Argentina, India, Ukraine, and Syria, with a lower number of accessions, was within the range of variability found for the cultivars grown under a Mediterranean climate. The present results show that the American cultivars are not less fatty than the European ones, as previously reported for a lower number of cultivars (García-López et al., 1996).

The analysis of variance showed that the effect of the genotype and the interaction genotype $\times$ year were significant for oil content, whereas the year effect was not significant (Table 2 ). The year effect has been reported to be significant for oil content in some studies (Abdallah et al., 1998; Barbera et al., 1994; Sathe et al., 2008), but not in others (Kodad and Socias i Company, 2008; Kodad et al., 2010; Romojaro et al., 1988). These discrepancies could be the result of the specific climatic conditions of the years tested (Socias i Company et al., 2008). Oil content in almond kernel shows a high heritability value of 57\% (Font i Forcada et al., 2011), confirming that the genetic 


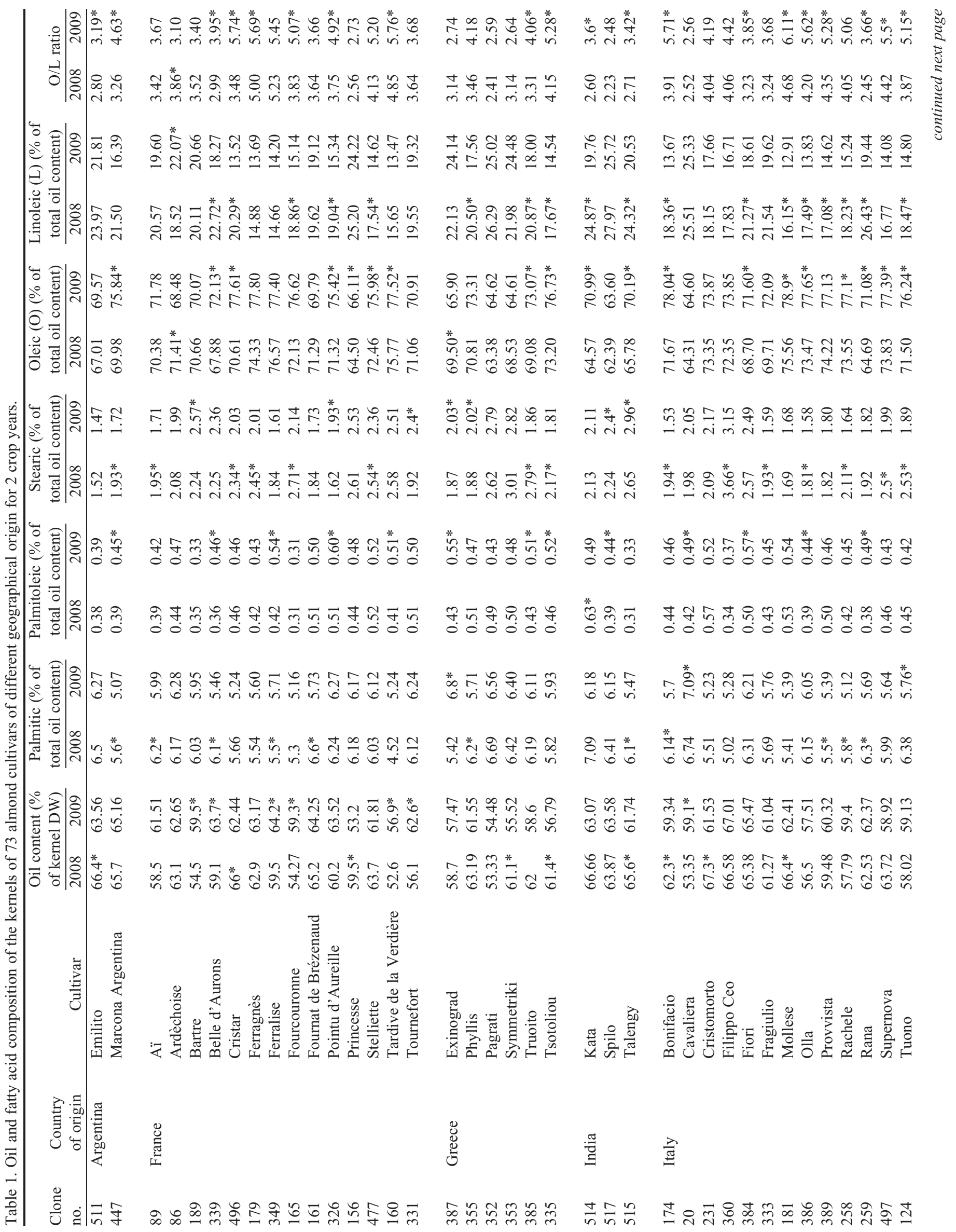




\begin{tabular}{|c|c|c|c|c|c|}
\hline 密 & 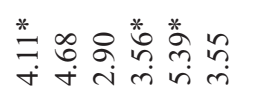 & 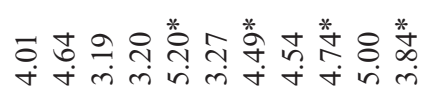 & $\stackrel{\infty}{\infty} \stackrel{*}{\stackrel{*}{\sim}}$ & 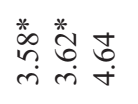 & 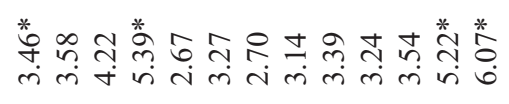 \\
\hline 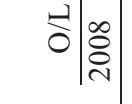 & 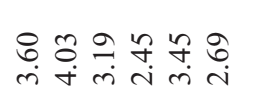 & 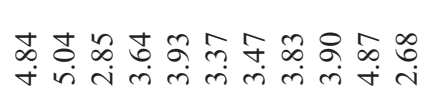 & $\hat{n} \stackrel{n}{m}$ & 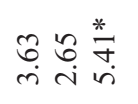 & 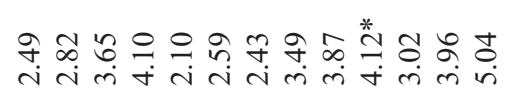 \\
\hline 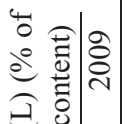 & 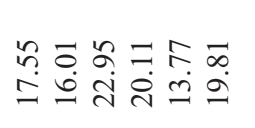 & 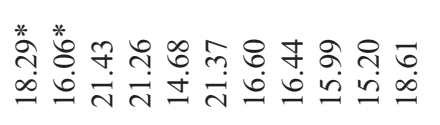 & $\begin{array}{l}\hat{R} \\
\stackrel{\infty}{\infty} \\
\stackrel{\infty}{=}\end{array}$ & 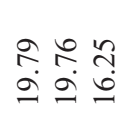 & 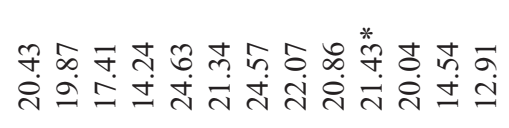 \\
\hline 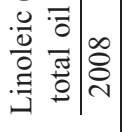 & 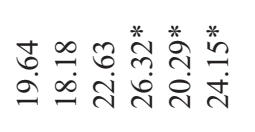 & 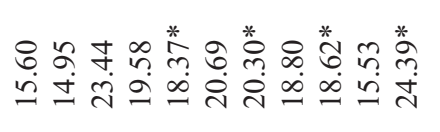 & 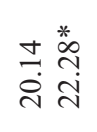 & 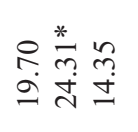 & 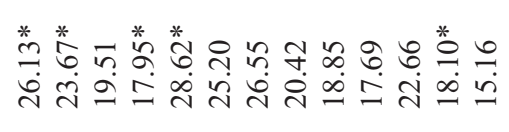 \\
\hline \begin{tabular}{ll|l|}
4 & $\overrightarrow{0}$ \\
0 & 0 \\
0 & 0 & 0 \\
0 & 0 & 0 \\
0 & 0 & 0
\end{tabular} & 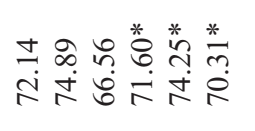 & 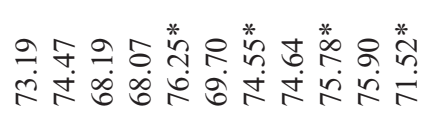 & $\begin{array}{l}g \\
\stackrel{2}{i} \\
\stackrel{n}{n}\end{array}$ & 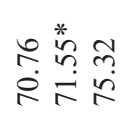 & 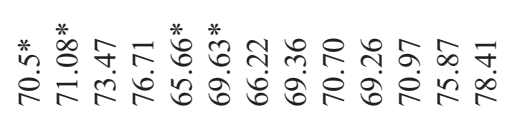 \\
\hline 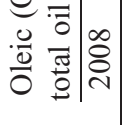 & 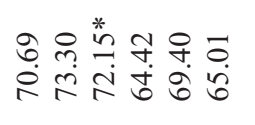 & 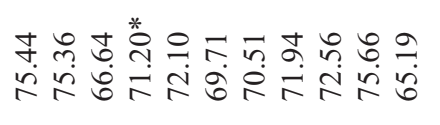 & $\begin{array}{l}\stackrel{1}{0} \\
\stackrel{0}{0} \\
\stackrel{0}{0}\end{array}$ & 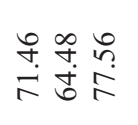 & 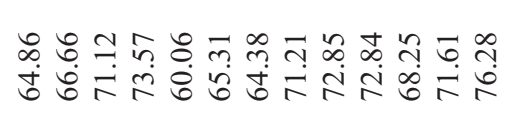 \\
\hline \begin{tabular}{ll|l|}
4 & $\overrightarrow{0}$ \\
0 & 0 & 0 \\
0 & 0 & 0 \\
0 & 0 & 0
\end{tabular} \mid & 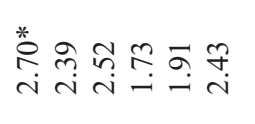 & 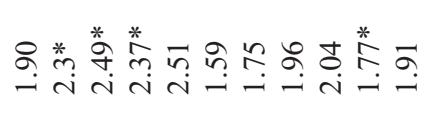 & 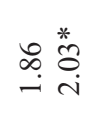 & 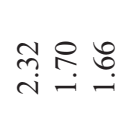 & 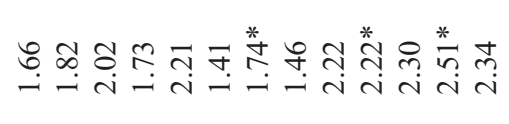 \\
\hline 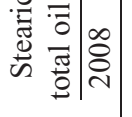 & 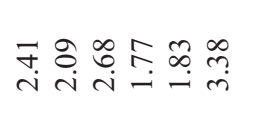 & 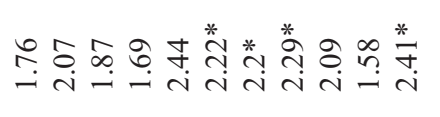 & $\stackrel{\infty}{\dddot{n}} \stackrel{\infty}{-}$ & 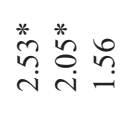 & 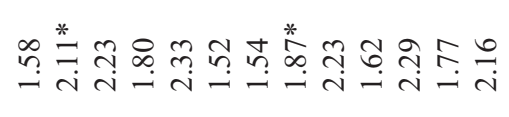 \\
\hline 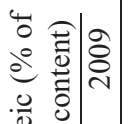 & 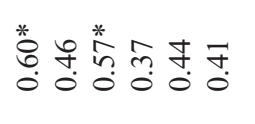 & 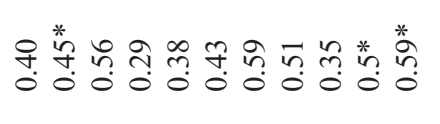 & 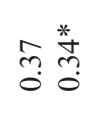 & స̂ำ & 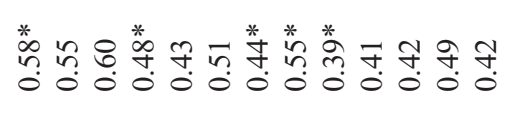 \\
\hline 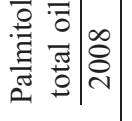 & 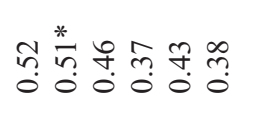 & 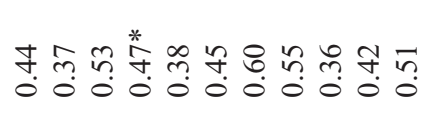 & $\stackrel{*}{*} \underset{0}{0}$ & 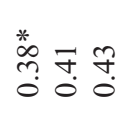 & 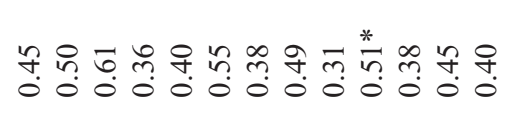 \\
\hline 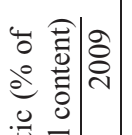 & 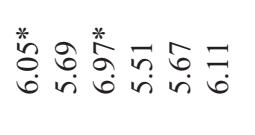 & 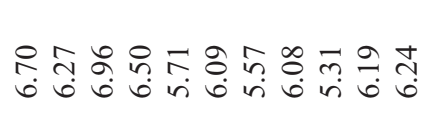 & $\begin{array}{l}\text { \& } \\
\text { in in }\end{array}$ & 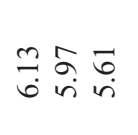 & 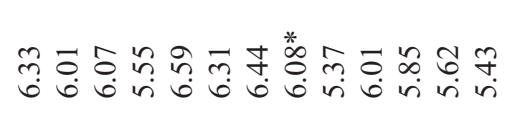 \\
\hline 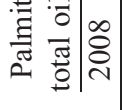 & 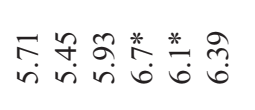 & 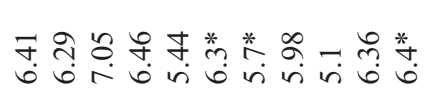 & 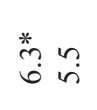 & 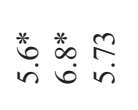 & Ұ̛ \\
\hline 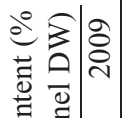 & 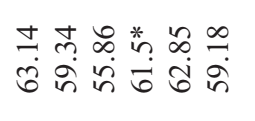 & 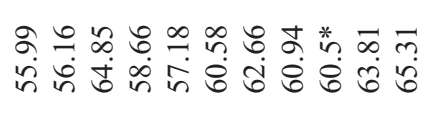 & 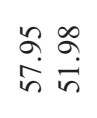 & 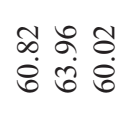 & 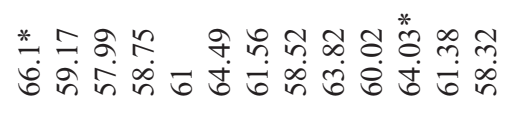 \\
\hline 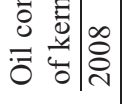 & 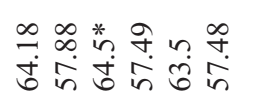 & 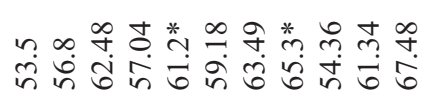 & $\frac{\infty}{b} \stackrel{\infty}{i}$ & 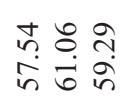 & 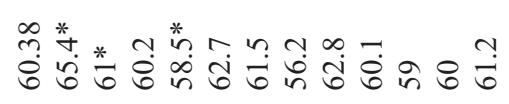 \\
\hline 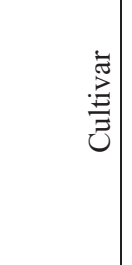 & 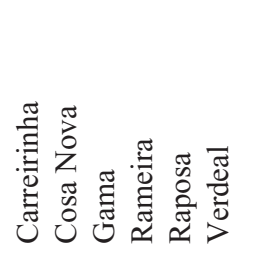 & 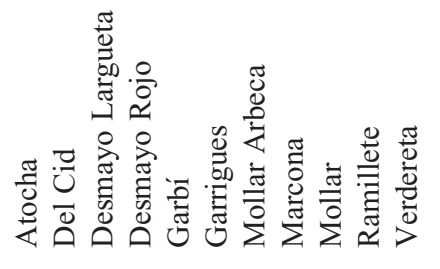 & 离兽 & 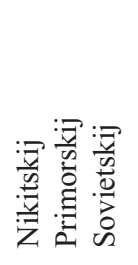 & 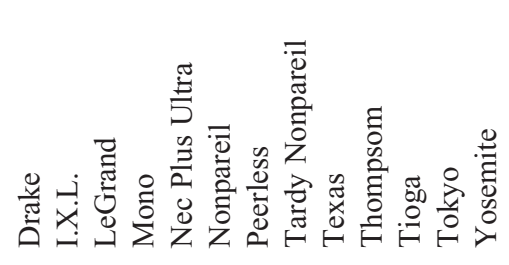 \\
\hline 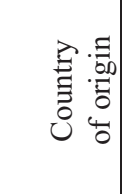 & $\begin{array}{l}\vec{F}_{0} \\
\stackrel{0}{0} \\
\stackrel{0}{0}\end{array}$ & $\begin{array}{l}\text { 䒕 } \\
\text { के }\end{array}$ & 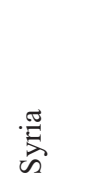 & $\begin{array}{l}\stackrel{\mathscr{\Xi}}{\pi} \\
\frac{\tilde{\Xi}}{5}\end{array}$ & 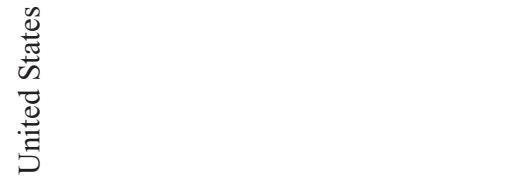 \\
\hline$\stackrel{0}{0}$ & 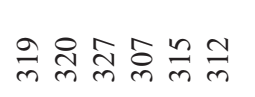 & 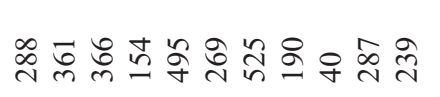 & $\begin{array}{l}\infty \\
\infty \\
\infty\end{array}$ & 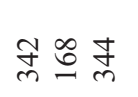 & $\hat{n} \boldsymbol{\infty} \tilde{\sim} \tilde{\hat{n}}$ \\
\hline
\end{tabular}


factor is the most determinant for oil content in almond kernels. This trait appears to be under polygenic control with a clear environmental effect (Abdallah et al., 1998; Kodad et al., 2010; Sathe et al., 2008). Thus, the magnitude of the effect of the external factors such as the climatic condition of the year probably depends on the genetic background of each cultivar, explaining the significant effect of the interaction genotype $\times$ year (Table 2).

The range of variability for the main fatty acids was also large. For palmitic acid it was from $4.88 \%$ in 'Tardive de la Verdière' to $7 \%$ in 'Desmayo Largueta'; for palmitoleic acid from $0.31 \%$ in 'Siria-3' to $0.6 \%$ in 'LeGrand'; for stearic acid from $1.46 \%$ in 'Nonpareil' to $3.4 \%$ in 'Filippo Ceo'; for oleic acid from $62.86 \%$ in 'Ne Plus Ultra' to $77.34 \%$ in 'Yosemite'; and for linoleic acid from $14.03 \%$ in 'Yosemite' to $26.84 \%$ in 'Spilo'. The largest range of variability of mean value of oleic acid over the 2 years was in the genetic pool from the United States $(62.86 \%$ to $77.34 \%)$ followed by those of France $(65.3 \%$ to $76.99 \%)$, Greece $(64 \%$ to $74.96 \%)$, Spain $(67.66 \%$ to $74.1 \%)$, and Portugal (67.66\% to $75.78 \%)$. The highest mean value of oleic acid percentage was found in the genetic pool from Italy $(72.9 \%)$ followed by France $(72.43 \%)$, Spain (72.21\%), Portugal (70.64\%), the United States (70.26\%), and Greece $(69.39 \%)$. For linoleic acid, the larger ranges of variability were found in the genetic pools from the United States (14.03\% to $26.6 \%)$ and France (14.28\% to $24.71 \%)$ and the lower in those from Portugal $(17.03 \%$ to $23.21 \%)$ and Spain (15.35\% to $22.44 \%$ ). The lowest values of linoleic acid were found in French, Italian, and American cultivars. Concerning the $\mathrm{O} / \mathrm{L}$ ratio, the highest values were found in the Spanish, Italian, and French pools and the lowest in the Greek pool (Table 1). However, no significant differences were found for the different fatty acids among the different geographical origins. Thus, the nutritional value and oil stability of the almond kernel depend on the genotype and not on the geographical origin.

The effects of genotype and year as well as the interaction genotype $\times$ year were significant for all fatty acids (Table 2). The largest differences among genotypes were found for oleic and linoleic acids. The year and environment effects on the fatty acid profile have been well studied in almond oil (Abdallah et al., 1998; Kodad and Socias i Company, 2008; Kodad et al., 2010; Sathe et al., 2008), reaching in all cases the conclusion that the genotype showed a larger effect than the environmental conditions. Because our objective was to identify the cultivars with stable profiles of fatty acid composition, mainly for high oleic and low linoleic acid contents, the focus was directed to these two components. These two fatty acids are the most important because they are present in higher amounts than the others as well as for their implication in oil quality. A higher $\mathrm{O} / \mathrm{L}$ ratio is associated with higher oil stability and lower rancidity (Kester et al., 1993) as well as to a higher nutritional value (Vezvaei and Jackson, 1996). 'Yosemite' from the United States, 'Del Cid' and 'Ramillete' from Spain, 'Tardive de la Verdière' and 'Ferralise' from France, and 'Sovietskij' from Ukrania showed high and stable values for oleic acid content and low values for linoleic acid during the 2 years studied (Table 1).

Correlation among variables. All variables were jointly examined and their correlation coefficients are shown in Table 3. No correlations were found between oil content and the percentage of the main fatty acids in both years of study with the only exception of a significant positive correlation between the contents of oil and of palmitic acid in 2008, although previous studies reported that oleic acid is positively correlated with oil content (Font i Forcada et al., 2011; Kodad and Socias i Company, 2008). A high negative correlation was found between palmitic and both the oleic acid and the $\mathrm{O} / \mathrm{L}$ ratio (Table 3).

A highly significant negative correlation was found between oleic and linoleic acids (Table 3 ), as previously reported in other almond genotypes and under different environmental conditions (Abdallah et al., 1998; Askin et al., 2007; Kodad and Socias i Company, 2006). This negative correlation may be explained by the fact that the pool of oleic acid appears to be

Table 2. Analysis of variance for oil content (percent of kernel dry weight) and fatty acid composition (percent of total oil content) of 73 almond cultivars.

\begin{tabular}{|c|c|c|c|c|c|c|c|c|}
\hline \multirow{2}{*}{$\begin{array}{l}\text { Source of } \\
\text { variation }\end{array}$} & \multirow[b]{2}{*}{$\mathrm{df}$} & \multicolumn{7}{|c|}{ Mean square ${ }^{\mathrm{z}}$} \\
\hline & & Oil & Palmitic & Palmitoleic & Stearic & Oleic $(\mathrm{O})$ & Linoleic (L) & $\mathrm{O} / \mathrm{L}$ ratio \\
\hline Genotype (G) & 72 & $39.5 * * *$ & $0.75 * * *$ & $0.01 * * *$ & $0.53 * * *$ & $51.67 * * *$ & $47.5 * * *$ & $2.8^{* * *}$ \\
\hline Year (Y) & 1 & $0.23 \mathrm{NS}$ & $1.03 * * *$ & $0.03 * * *$ & $0.35 * * *$ & $380.4 * * *$ & $371.6 * * *$ & $24.6 * * *$ \\
\hline $\mathrm{G} \times \mathrm{Y}$ & 72 & $12.1 * * *$ & $0.17 * * *$ & $0.003^{* *}$ & $0.11 * * *$ & $9.1 * * *$ & $6.9^{* * *}$ & $0.46^{* * *}$ \\
\hline Error & 146 & 0.59 & 0.02 & 0.0012 & 0.008 & 0.54 & 1.49 & 0.01 \\
\hline
\end{tabular}

$\mathrm{z}_{\mathrm{NS}}, * *, * * *$ Non-significant or significant at $P<0.001$ and 0.0001 , respectively.

Table 3. Correlations between oil content (percentage of kernel dry weight) and the different fatty acid concentrations (percentage of total oil content) in the kernels of 73 almond cultivars for the 2008 and 2009 crop years. $^{\mathrm{z}}$

\begin{tabular}{|c|c|c|c|c|c|c|c|}
\hline Variable & $\mathrm{Yr}$ & Oil & Palmitic & Palmitoleic & Steraic & Oleic & Linoleic \\
\hline \multirow[t]{2}{*}{ Palmitic } & 2008 & 0.12 & & & & & \\
\hline & 2009 & -0.14 & & & & & \\
\hline \multirow[t]{2}{*}{ Palmitoleic } & 2008 & $0.38 *$ & 0.29 & & & & \\
\hline & 2009 & 0.21 & 0.27 & & & & \\
\hline \multirow[t]{2}{*}{ Steraic } & 2008 & 0.07 & -0.24 & -0.14 & & & \\
\hline & 2009 & -0.14 & 0.09 & -0.19 & & & \\
\hline \multirow[t]{2}{*}{ Oleic $(\mathrm{O})$} & 2008 & -0.09 & $-0.43 * *$ & 0.02 & -0.11 & & \\
\hline & 2009 & 0.05 & $-0.33 * *$ & 0.01 & -0.27 & & \\
\hline \multirow[t]{2}{*}{ Linoleic (L) } & 2008 & 0.08 & $0.44 * *$ & -0.05 & 0.06 & $-0.98 * *$ & \\
\hline & 2009 & -0.06 & $0.55 * *$ & -0.05 & 0.19 & $-0.98 * *$ & \\
\hline \multirow[t]{2}{*}{$\mathrm{O} / \mathrm{L}$ ratio } & 2008 & -0.10 & $-0.53 * *$ & 0.01 & -0.09 & $0.96 * *$ & $-0.98 * *$ \\
\hline & 2009 & 0.01 & $-0.63 * *$ & 0.04 & -0.19 & $0.97 * *$ & $-0.98 * *$ \\
\hline
\end{tabular}

${ }^{\mathrm{z}}$ Correlations in bold are significant at $* P<0.1$ and ${ }^{* *} 0.01$. 
controlled by its conversion to linoleic, probably as a result of the enzymatic activity of oleic desaturase (Garcia et al., 1992). Correlation coefficients greater than 0.71 or smaller than -0.71 have been suggested to be biologically meaningful (Skinner et al., 1999), showing that this correlation is not influenced by climatic and environmental conditions and is genotype-dependent. Thus, the selection for one of these fatty acids could negatively modify the amount of the other.

Principal COMPONENT ANAlysis. Chemometric characterization is a useful way for describing and classifying plant germplasm. Statistical methods such as PCA and cluster analysis can be useful tools for screening genotypes in plant collections, including almond (García-López et al., 1996; Lansari et al., 1994), olive [Olea europea L. (Cantini et al., 1999)], loquat [Eryobotrya japonica (Thunb.) Lindl. (Martínez-Calvo et al., 2008)], peach (Nikolić et al., 2010), and apricot [Prunus armeniaca L. (Gurrieri et al., 2001)]. The PCA was applied to the data of each year as a result of the significance of the genotype $\times$ year interaction (Table 2), thus indicating a different genotypic behavior in relation to the year. To select the best model with the minimum number of dimensions explaining the data structure, the exclusion rule used was based on the amount of residual variability to tolerate, retaining a sufficient number of PCs capable of explaining a percentage of variance greater than $80 \%$. Using this rule, the first three PCs are enough because they described $85.38 \%$ (2008) and 83.34\% (2009) of the sample variability. The contribution of each PC to the total variance is shown in Table 4 . In both years, the palmitic, oleic, and linoleic acids and the $\mathrm{O} / \mathrm{L}$ ratio were primarily responsible for the separation on the PC1. In 2008, the second component was highly correlated to oil content and palmitoleic acid and the third component was represented by stearic acid. In 2009, the second component is represented by palmitoleic and stearic acids and the third component by oleic acid.

In 2008, when the means were plotted on the three principal axes (Fig. 1), 'Tardive de la Verdière' and 'Ferralise' from France, 'Sovietskij' from Ukraine, 'Yosemite' from the United States, 'Mollese' from Italy, and 'Del Cid' and 'Mollar' from Spain had a positive value on PC1. These showed high values for oleic acid content and the $\mathrm{O} / \mathrm{L}$ ratio, low values for linoleic and palmitic acids, and medium values for oil content with the exception of 'Mollese', showing high oleic content and stearic acid (Table 1). This cultivar has high positive value on PC2 and

Table 4. Eigenvectors of the three principal component (PC) axes of the kernel composition after principal component analysis of 73 almond cultivars for 2 crop years. ${ }^{\mathrm{z}}$

\begin{tabular}{lrrrrrrr}
\hline & \multicolumn{3}{c}{ Crop yr 2008 } & & \multicolumn{3}{c}{ Crop yr 2009 } \\
\cline { 2 - 4 } Variable & PC1 & PC2 & PC3 & & PC1 & PC2 & PC3 \\
\hline Oil content & -0.09 & 0.54 & 0.44 & & 0.05 & 0.49 & 0.82 \\
Palmitic acid & -0.38 & 0.31 & -0.29 & & -0.41 & 0.22 & -0.37 \\
Palmetoleic acid & -0.04 & 0.70 & 0.11 & -0.01 & 0.69 & -0.32 \\
Stearic acid & -0.02 & -0.33 & 0.78 & & -0.15 & -0.48 & 0.22 \\
Oleic acid (O) & 0.53 & 0.11 & -0.03 & & 0.52 & 0.00 & -0.09 \\
Linoleic acid (L) & -0.53 & -0.13 & 0.00 & -0.52 & 0.00 & 0.09 \\
O/L ratio & 0.53 & 0.11 & -0.05 & & 0.51 & -0.01 & -0.14 \\
Eigenvalue & 3.36 & 1.48 & 1.13 & & 3.54 & 1.36 & 0.92 \\
Proportion of & 48.08 & 21.15 & 16.15 & & 50.57 & 19.49 & 13.28 \\
$\quad$ total (\%) & & & & & & \\
\hline
\end{tabular}

${ }^{\mathrm{z}}$ Eigenvalues and their contribution to total variation are listed at the bottom of columns.
PC3 (Fig. 1). In contrast, 'Ne Plus Ultra', 'Drake', 'Peerless', and 'Nonpareil' from the United States; 'Spilo' and 'Kata' from India; 'Pagrati' from Greece; 'Rameira' and 'Verdeal' from Portugal; 'Cavaliera' and 'Rana' from Italy; 'Prismorkij' from Ukraine; 'Princesse' from France and 'Desmayo Largueta'; and 'Verdereta' from Spain showed high values for linoleic acid and low values for oleic and the O/L ratio (Table 1). 'Verdereta', 'Nonpareil', 'Kata', and 'Desmayo Largueta' showed high values for oleic content and stearic acid, whereas in the rest of the genotypes, these values were low. The remaining cultivars showed intermediate values for the variables explaining the first principal component (Table 4). High similarities were found between 'Olla' and 'Rachelle' and between 'Mollar Arbeca' and 'LeGrand' (Fig. 1).

In 2009, 'Fourcouronne', 'Ferragnès', 'Ferralise', 'Cristar', and 'Tardive de la Verdière' from France; 'Supernova', 'Provvista', 'Rachele', 'Bonifacio', 'Olla', and 'Mollese' from Italy; 'Mono' and 'Yosemite' from the United States; and 'Ramillete' from Spain showed low values for linoleic acid and high values for oleic acid and $\mathrm{O} / \mathrm{L}$ ratio (Table 1). 'Ramillete', 'Ferralise', and 'Mollese showed high contents of oleic and stearic acids. However, 'Cavaliera' from Italy; 'Pagrati', 'Exinogrand', and 'Symmetriki' from Greece; 'Spilo' from India; 'Gama' from Portugal; 'Ne Plus Ultra' and 'Thompson' from the United States; 'Desmayo Largueta' and 'Desmayo Rojo' from Spain; and 'Ardèchoise' and 'Princesse' from France showed high values for linoleic acid and low values for oleic acid and $\mathrm{O} / \mathrm{L}$ ratio. 'Desmayo Largueta' showed high values for oleic and stearic acids. When comparing the oil content and fatty acid profiles, the results revealed high similarities between 'Tuono' and 'Tokyo' and between 'Rana' and 'Carreirinha' (Fig. 2).

'Ferralise', 'Ferragnès', 'Fourcoronne', and 'Tardive de la Verdière' from France; 'Mollar' and 'Ramillete' from Spain; 'Supernova', 'Provvista', and 'Mollese' from Italy; and 'Yosemite' and 'Mono' from the United States showed consistent high oleic acid and O/L ratio and low linoleic acid. 'Ramillete' and 'Mollese' showed high and stable oleic content during the 2 years of study.

The results of the PCA confirmed that oleic and linoleic acids and the $\mathrm{O} / \mathrm{L}$ ratio are important criteria for quality characterization of almond cultivars. However, the use of these variables for identifying almond cultivars and establishing phylogenetic relationship among them (Grané-Teruel et al., 2001 ) is not recommended because of the high year effect on their expression as reported in this and other studies (Abdallah et al., 1998; Kodad et al., 2010; Sathe et al., 2008). Some cultivars such as 'Olla' and 'Rachelle' in one side and 'Mollar Arbeca' and 'LeGrand' in the other showed similar oil and fatty acid profiles in 2008 (Fig. 1), but not in 2009, when they were separated and ranged with other cultivars (Fig. 2). The clustering of genotypes using the variability observed does not allow their classification according to their geographical origin, confirming that the oil content and the fatty acid profile depend primarily on the genotype and not on the geographical provenance.

BrEEDING IMPLICATIONS. The trend of the modern almond industry in requiring kernels with high-quality attributes as well as that of consumers for foods without synthetic additives involve not only the incorporation of the chemical quality criteria in the evaluation of the new cultivars (Kodad et al., 2004, 2006), but also considering these traits in the breeding programs (Socias i Company et al., 2008). Several studies have been undertaken to understand the environmental effects on these variables (Abdallah et al., 1998; Kodad et al., 2010; Sathe et al., 


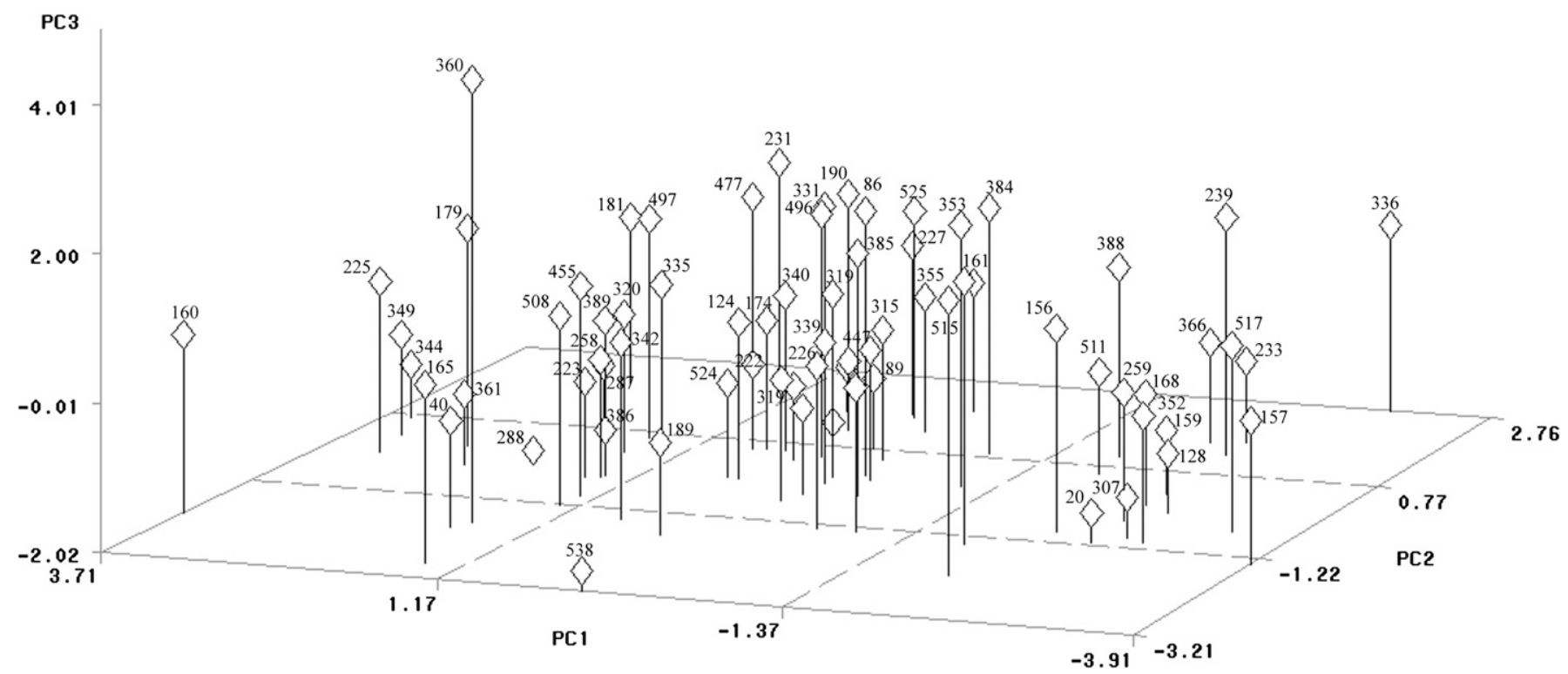

Fig. 1. Position of the principal component (PC) scores of the almond kernel composition for 73 almond cultivars in the 2008 crop year. Numbers refer to the clone number of the cultivar (Table 1).

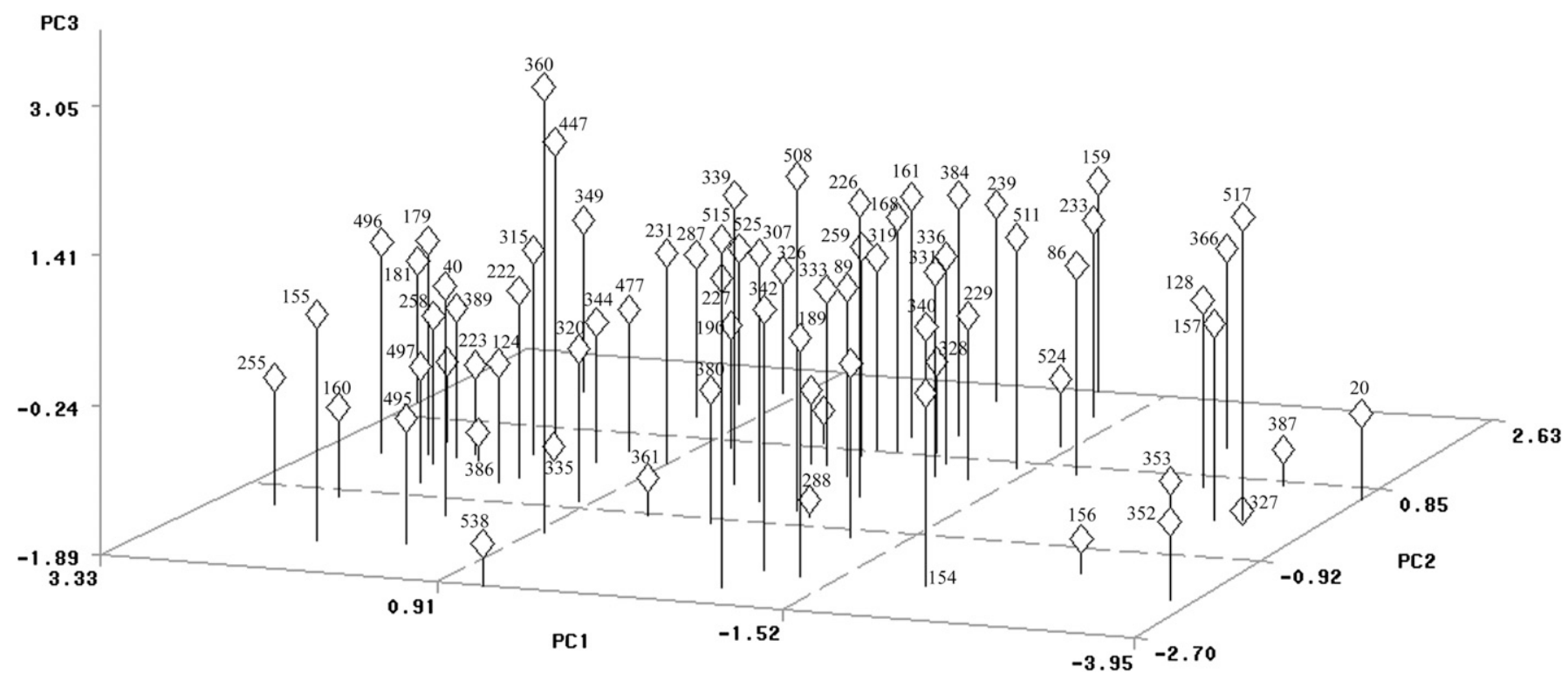

Fig. 2. Position of the principal component (PC) scores of the almond kernel composition for 73 almond cultivars in the 2009 crop year. Numbers refer to the clone number of the cultivar (Table 1).

2008), the variability of these components in the almond progenies (Kodad and Socias i Company, 2008), the correlation among these traits in different almond cultivars and selections (Askin et al., 2007; Font i Forcada et al., 2011; Kodad and Socias i Company, 2006), and their heritability and transmission to the offspring (Font i Forcada et al., 2011). All this information is useful to select the trait to be improved, the parents involved in the cross, and also the sense of the cross.

Oil content and linoleic acid have shown high (0.57) and medium (0.25) heritabilities, respectively (Font i Forcada et al., 2011). A trait with high heritability indicates an additive gene action (Johnson et al., 1955; Yao and Mehlenbacher, 2000) and the trait will be less influenced by environmental effects. Thus, selection for these traits will be more effective because they are less influenced by the environment. With medium heritability estimates, selection of parents based on their phenotypes should also be effective, as it happens when heritability is high (Hansche et al., 1972). Thus, selection for high oil content and low linoleic acid could be undertaken to improve almond kernel quality and stability, because a low linoleic acid is related to high oil stability (Zacheo et al., 2000).

Significant differences for oil content and linoleic acid were found among several breeding families (Font i Forcada et al., 2011). Even with parents with medium to high values of oil content, the progeny mean was high, showing the possibility of increasing the oil content in the progeny (greater than $55 \%$ 
DW). With parents showing low values for linoleic acid, the progeny mean was also low, thus showing an efficient way to reduce the content of linoleic acid in the offspring.

Correlation coefficients allow comparing indirect and direct selection, thus computing the correlated response for a second trait when selection pressure is applied to a first one and allowing establishing a selection strategy (Falconer and Mackay, 1996). The high negative correlation between oleic acid and linoleic acid found in both years $\left(r^{2}=-0.98\right)$ agrees with other reports (Abdallah et al., 1998; Askin et al., 2007; Kodad and Socias i Company, 2008), and indicates the possibility of an indirect selection for high oleic acid by selecting low linoleic acid. The $\mathrm{O} / \mathrm{L}$ ratio is an important index for evaluating oil stability against rancidification in almond (Kester, et al., 1993), and is considered an important criterion to evaluate kernel quality (Socias i Company et al., 2008). Thus, selection for low linoleic acid will not only increase the content of oleic acid, but also increase oil quality and stability. The lack of significant correlations between oil content and linoleic acid allows selecting one trait without modifying the other. The lack of significant correlations between the chemical components and the physical traits of the almond kernel (Kodad and Socias i Company, 2006) points out to the possibility of attempting almond breeding for kernel chemical composition without losing the advances obtained in breeding for physical quality.

The evaluation of the variability and stability of these chemical components in 73 almond cultivars from different geographical origin (10 countries) is furnishing important information for breeders. In addition, this information is also extremely valuable for the industry to choose the adequate cultivars for each confectionery, because kernels with a high percentage of oil could be used to produce nougat or to extract oil, which is used in the cosmetic and pharmaceutical industries (Socias i Company et al., 2008). Furthermore, high oil content with a high $\mathrm{O} / \mathrm{L}$ ratio is very important to increase the shelf life of oil and the derivate products during the time from field to consumption. Consequently, the wide variability of the chemical components of the almond kernel and their heritability allow recommending some cultivars with medium to high and stable oil content and low linoleic acid as parents in almond breeding programs to increase kernel oil stability and nutritional value.

\section{Literature Cited}

Abdallah, A., M.H. Ahumada, and T.M. Gradziel. 1998. Oil content and fatty acid composition of almond kernels from different genotypes and California production regions. J. Amer. Soc. Hort. Sci. 123:1029-1033.

Alessandroni, A. 1980. Le mandorle. Panificazione e Pasticceria 8:6771.

Askin, M.A., M.F. Balta, F.E. Tekintas, A. Kazankaya, and F. Balta. 2007. Fatty acid composition affected by kernel weight in almond. [Prunus dulcis (Mill.) D.A. Webb.]. J. Food Compost. Anal. 20:7-12.

Barbera, G., L. Di Marco, T. La Mantia, and M. Schirra. 1994. Effect of rootstock on productive and qualitative response of two almond varieties. Acta Hort. 373:129-134.

Berger, P. 1969. Aptitude à la transformation industrielle de quelques variétés d'amandier. Bulletin Technique d'Information 241:577580 .

Cantini, C., A. Cimato, and G. Sani. 1999. Morphological evaluation of olive germplasm present in Tuscany region. Euphytica 109:173181.

Espiau, M.T., J.M. Ansón, and R. Socias i Company. 2002. The almond germplasm bank of Zaragoza. Acta Hort. 591:275-278.
Falconer, D.S. and T.F.C. Mackay. 1996. Introduction to quantitative genetics. 4th Ed. Prentice Hall, Harlow, UK.

Felipe, A.J. 1977. Almendro: Estados fenólogicos. Información Técnica Económica Agraria 27:8-9.

Felipe, A.J. 2000. El almendro. I. El material vegetal. Integrum, Lleida, Spain.

Font i Forcada, C., O. Kodad, T. Juan, G. Estopañán, and R. Socias i Company. 2011. Genetic variability and pollen effect on the transmission of the chemical components of the almond kernel. Span. J. Agr. Res. (in press).

Garcia, J.M., I.T. Agar, and J. Streif. 1992. Fat content and fatty acid composition in individual seeds of pistachio varieties grown in Turkey. Gartenbauwissenschaft 57:130-133.

García-López, C., N. Grané-Teruel, V. Berenguer-Navarro, J.E. García-García, and M.L. Martín-Carratalá. 1996. Major fatty acid composition of 19 almond cultivars of different origins. A chemometric approach. J. Agr. Food Chem. 46:963-967.

Grané-Teruel, N., M.S. Prats-Moya, V. Berenguer-Navarro, and M.L. Martín-Carratalá. 2001. A possible way to predict the genetic relatedness of selected almond cultivars. J. Amer. Oil Chem. Soc. 78:617-619.

Grasselly, C. 1972. L'amandier: Caractères morphologiques et phsyiologiques des variétés, modalité de leurs transmissions chez les hybrides de première genération. PhD thesis, Univ. Bordeaux, Bordeaux, France.

Gurrieri, F., J.M. Audergon, G. Albagnac, and M. Reich. 2001. Soluble sugars and carboxylic acids in ripe apricot fruit as parameters for distinguishing different cultivars: Use of principle component analysis to characterize apricot fruit quality. Euphytica 117:183-189.

Hansche, P.E., W. Beres, and H.I. Forde. 1972. Estimate of quantitative genetic properties of walnut and their implication for cultivar improvement. J. Amer. Soc. Hort. Sci. 97:279-285.

Iezzoni, A.F. and M.P. Pritts. 1991. Applications of principal components analysis to horticultural research. HortScience 26:334-338.

International Organization for Standardization. 2000. Animal and vegetable fats and oils-Preparation of methyl esters of fatty acids. ISO Standard 5509. ISO, Geneva, Switzerland.

Johnson, H.W., H.F. Robinson, and R.W. Comstock. 1955. Estimates of genetic and environmental variability in soybeans. Agron. J. 47: 314-318.

Kester, D.E. and R. Asay. 1975. Almonds, p. 387-419. In: Janick, J. and J.N. Moore (eds.). Advances in fruit breeding. Purdue University Press, West Lafayette, IN

Kester, D.E., S. Cunningham, and A.A. Kader. 1993. Almonds, p. 121126. In: Encyclopedia of food science, food technology and nutrition. Academic Press, London, UK.

Kester, D.E., T.M. Gradziel, and C. Grasselly. 1990. Almonds (Prunus). Acta Hort. 290:699-758.

Kodad, O., G. Estopañán, T. Juan, F. Molino, A. Mamouni, Z. Messaoudi, M. Lahlou, and R. Socias i Company. 2010. Plasticity and stability in the major fatty acid content of almond kernels grown under two Mediterranean climates. J. Hort. Sci. Biotechnol. 85:381-386.

Kodad, O. and R. Socias i Company. 2006. Phenotypic correlation between some agrochemical traits of the almond kernel. Acta Hort. 726:259-264.

Kodad, O. and R. Socias i Company. 2008. Variability of oil content and of major fatty acid composition in almond (Prunus amygdalus Batsch) and its relationship with kernel quality. J. Agr. Food Chem. 56:4096-4101.

Kodad, O., R. Socias i Company, M.S. Gracia Gómez, J.M. Martínez Lázaro, and A. Bonilla. 2004. La composición de la almendra como criterio para su utilización industrial y como base para la selección en un programa de mejora genética. Actas III Congreso Español de Ingeniería de Alimentos, Pamplona, Spain. p. 1094-1102.

Kodad, O., R. Socias i Company, M.S. Prats, and M.C. López Ortiz. 2006. Variability in tocopherol concentrations in almond oil and its use as a selection criterion in almond breeding. J. Hort. Sci. Biotechnol. 81:501-507. 
Krings, U. and R.G. Berger. 2001. Antioxidant activity of some roasted foods. Food Chem. 72:223-229.

Lansari, A., A.F. Iezzoni, and D.E. Kester. 1994. Morphological variation within collections of Moroccan almond clones and Mediterranean and North American cultivars. Euphytica 78:2741.

Martínez-Calvo, J., A.D. Gisbert, M.C. Alamar, R. Hernandorena, C. Romero, G. Llácer, and M.L. Badenes. 2008. Study of a germplasm collection of loquat (Eriobotrya japonica Lindl.) by multivariate analysis. Genet. Resources Crop Evol. 55:695-703.

Nikolić, D., V. Rakonjac, D. Milatović, and M. Fotirić. 2010. Multivariate analysis of vineyard peach [Prunus persica (L.) Batsch.] germplasm collection. Euphytica 171:227-234.

Prosperi, J.M., E. Jenczewski, M. Angevain, and J. Ronfort. 2006. Morphologic and agronomic diversity of wild genetic resources of Medicago sativa L. collected in Spain. Genet. Resources Crop Evol. 53:843-856.

Rikhter, A.A. 1972. Biological bases for the creation of almond cultivars and commercial orchards [in Russian]. Glavny Botanical Garden, Moscow, Russia.

Romojaro, F., F. Riquelme, J.J. Gimenez, and S. Llorente. 1988. Fat content and oil characteristics of some almond varieties. Fruit Sci. Rpt. 15:53-57.

Sabate, J. and D.G. Hook. 1996. Almonds, walnuts, and serum lipids, p. 137-144. In: Spiller, G.A. (ed.). Lipids in human nutrition. CRC Press, Boca Raton, FL.
Sathe, S.K., N.P. Seram, H.H. Kshirsagar, D. Heber, and K.A. Lapsley. 2008. Fatty acid composition of California grown almonds. J. Food Sci. 73:C607-C614.

Senessi, E., A. Rizzolo, C. Colombo, and A. Testoni. 1996. Influence of pre-processing storage conditions on peeled almond quality. Italian J. Food Sci. 2:115-125.

Skinner, D.Z., G.R. Bauchan, G. Auricht, and S. Hughes. 1999. A method for the efficient management and utilization of large germplasm collections. Crop Sci. 39:1237-1242.

Socias i Company, R. and A.J. Felipe. 1992. Almond: A diverse germplasm. HortScience 27:717-718, 863.

Socias i Company, R., J. Gómez Aparisi, J.M. Alonso, M.J. RubioCabetas, and O. Kodad. 2009. Retos y perspectivas de los nuevos cultivares y patrones de almendro. Información Técnica Económica Agraria 105:99-116.

Socias i Company, R., O. Kodad, J.M. Alonso, and T.M. Gradziel. 2008. Almond quality: A breeding perspective. Hort. Rev. 34:197-238.

Vezvaei, A. and J.F. Jackson. 1996. Almond nut analysis, p. 135-148. In: Linskens, H.F. and J.F. Jackson (eds.). Modern methods of plant analysis. Vol. 18. Fruit analysis. Springer-Verlag, Berlin, Germany.

Yao, Q. and S.A. Mehlenbacher. 2000. Heritability, variance components and correlation of morphological and phenological traits in hazelnut. Plant Breed. 119:369-381.

Zacheo, G., M.S. Capello, A. Gallo, A. Santino, and A.R. Capello. 2000. Changes associated with postharvest ageing in almond seeds. Lebensmittel-Wissenschaft und-Technologie 33:415-423. 